SABRAO Journal of Breeding and Genetics

53 (4) 673-684, 2021

http://doi.org/10.54910/sabrao2021.53.4.10

http://sabraojournal.org/

pISSN 1029-7073; eISSN 2224-8978

\title{
ASSESSMENT OF TEA PLANT (CAMELLIA SINENSIS L.) ACCESSIONS FOR POLLEN SOURCES IN NATURAL CROSSING BY USING MICROSATELLITES
}

\author{
N.A. AZKA ${ }^{1 *}$, TARYONO ${ }^{1,2}$ and R.A. WULANDARI ${ }^{1}$ \\ ${ }^{1}$ Faculty of Agriculture, Gadjah Mada University, Yogyakarta, Indonesia \\ ${ }^{2}$ Agrotechnology Innovation Centre, Gadjah Mada University, Yogyakarta, Indonesia \\ *Corresponding author email: nafila.alifia.a@mail.ugm.ac.id \\ Email addresses of co-authors: tariono60@gmail.com, tariono60@ugm.ac.id, rani.akyun@gmail.com
}

\section{SUMMARY}

Tea (Camellia sinensis L. [O.] Kuntze) is a highly cross-pollinated and self-incompatible plant. Seeds can be harvested from specific individual mother plants in polyclonal tea gardens. Whether the pollen donor plays an important role in seed formation remains unclear. This study aimed to identify the male parents of 72 natural hybridized progenies $\left(F_{1}\right)$ from one female parent on the basis of a putative specific allele by using simplesequence repeat (SSR) markers and the exclusion-likelihood method with Cervus 3.0 software. The genetic material, which comprised seven accessions of $C$. sinensis L., was acquired from Assamica planted in the Kayulandak polyclonal seed garden of the Pagilaran tea plantation in Batang District, Central Java, Indonesia, and was studied during 2019 and 2020. The genotype PGL-15 was used as the female parent, whereas the six candidate genotypes PGL-10, GMB-9, GMB-7, TPS-93, GMB-11, and TRI-2025 were used as the male parents. In this study, 13 SSR loci were used to identify the male parents of the $F_{1}$ progenies obtained through natural hybridization between one female and six male tea accessions. Results indicated that the exclusion-likelihood method, which correctly predicted $100 \%$ of the male parents, was more effective than the putative specific allele approach, which correctly predicted only $34.72 \%$ of the male parents in the 72 hybridized $F_{1}$ progenies of tea plants.

Keywords: Camellia sinensis L., natural pollination, SSR markers, paternity analysis, putative specific allele, exclusion-likelihood method

Key findings: The exclusion-likelihood approach was found to be more effective than putative specific allele analysis in the prediction of the male parents of $F_{1}$ tea plant progenies. The exclusion-likelihood method correctly predicted $100 \%$ of the male parents, whereas the putative specific allele method was able to predict only $34.72 \%$ of the male parents of 72 hybridized $F_{1}$ progenies.

Manuscript received: May 25, 2021; Accepted: September 21, 2021.

(C) Society for the Advancement of Breeding Research in Asia and Oceania (SABRAO) 2021

Communicating Editor: Dr. Samrin Gul 


\section{INTRODUCTION}

Tea (Camellia sinensis), the oldest popular caffeine-containing beverage in the world, originated from China and the northeastern region of India (Akula and Akula, 1999; Chen et al., 2008). The global tea demand has increased with time due to population growth and improved life habits. The biochemical components of tea leaves include polyphenols, alkaloids, volatile compounds, polysaccharides, amino acids, lipids, and vitamins and demonstrate a variety of bioactivities.

Given that tea is a highly crosspollinated and self-incompatible plant (Bandyopadhyay, 2011), controlled pollination can be performed by harvesting legitimate seeds from mother plants through natural hybridization and genetically identifying potential male parents through parentage analysis (Diaz et al., 2006). Although biclonal seed cultivars are currently rarely used to produce appropriate planting material, exsitu field conservation banks still maintain their tea accessions by using polyclonal seed garden approaches. Such seed gardens can be utilized directly for breeding. Although controlled hybridization and individual selection have gradually become the predominant methods for tea breeding, tea breeding remains dependent on natural crossing for gene recombination due to the issues of self-incompatibility and inefficient artificial crossing (Muoki et al., 2007).

The prolonged cross-pollination of tea plants has produced considerable heritable variation, which has in turn resulted in a high level of genetic diversity (Fan et al., 2011; Kottawa-Arachchi et al., 2019). New high-yielding tea cultivars in the form of clonal plants can be exploited to increase yield. These tea cultivars can be selected individually from a population that originated from orchard seedlings or open-pollinated progenies.

The use of molecular techniques for parentage analysis has thrived over several decades. A highly polymorphic marker is required for successful parentage analysis, and microsatellite markers have been identified as the most reliable tool for the parentage analysis of peach (Prunus persica L.) (Yamamoto et al., 2002), oil palm (Thongthawae et al., 2010), and polyploid sweet potato (Buteler and LaBonte, 2002) due to their codominant inheritance and large number of alleles per loci.

The introduction of microsatellite markers into molecular ecology, accompanied by the proliferation and refinement of statistical techniques for the analysis of the parentage data of natural populations (Jones and Arden, 2003), is the most important technological innovation. As a result, parentage analysis can be performed as one of the most efficient and accurate analyses with simple-sequence repeat (SSR) markers.

ast studies have also classified different approaches for parentage analysis, i.e., exclusion, categorical allocation, fractional allocation, full probability parentage analysis, parental reconstruction, and sibship reconstruction (Jones et al., 2010). Mookerjee et al. (2005) proved that in olive plants, the chance of cumulative exclusion is very high because SSRs show a very low error probability in recognizing the male parent. Therefore, on the basis of the the above discussion, this study aimed to explore a similar approach for identifying the male parents of 72 seedling progenies of natural tea crosses. Male parent determination in open-pollinated progeny is useful for reconstructing the pedigree of outcrossed crops (Norman et al., 2018). Reliable pedigree information is useful for breeders in making decisions on existing divergence in progeny and hybrid vigor (Spanoghe et al., 2015) and determining genetic estimates, breeding value, and relationships (Gjedrem, 2010).

\section{MATERIALS AND METHODS}

\section{Plant material}

The genetic material, which comprised seven accessions and 72 hybridized $F_{1}$ 
progenies of $C$. sinensis L., was acquired from Assamica planted in the Kayulandak polyclonal seed garden of the Pagilaran tea plantation in Batang District, Central Java, Indonesia, and was studied during 2019 and 2020. The genotype PGL-15 was used as the female parent, whereas the six candidate genotypes PGL-10, GMB-9, GMB-7, TPS-93, GMB-11, and TRI-2025 were used as the male parents. The $72 F_{1}$ progenies were obtained through natural hybridization.

\section{DNA extraction and amplification}

DNA was extracted from tea leaves by using the modified cetyltrimethylammonium bromide (CTAB) method (Doyle and Doyle, 1990). A total of $200 \mathrm{mg}$ of dry tea leaves was ground into smooth powder and added with 1500 $\mu \mathrm{l}$ of extraction buffer solution ( $2 \%$ CTAB, $0.1 \mathrm{M}$ Tris-hydrochloric acid $\mathrm{pH} 8.0,1.4 \mathrm{M}$ sodium chloride, $0.02 M$ EDTA, 2\% polyvinyl pyrrolidone, $2 \% \quad \beta$ mercaptoethanol, and aqua-bidest). The extracted solution was then transferred into a $1.5 \mathrm{ml}$ microtube and incubated in a water bath at $65^{\circ} \mathrm{C}$ for $60 \mathrm{~min}$. The solution was added with $500 \mu \mathrm{ll}$ of chloroform isoamyl alcohol, then homogenized with a vortex and centrifuged at $12000 \mathrm{rpm}$ for $15 \mathrm{~min}$. The last step was repeated three times. The supernatant was then transferred into a $1.5 \mathrm{ml}$ microtube, then added with $60 \mu \mathrm{l}$ of sodium acetate and $440 \mu \mathrm{l}$ of isopropanol and stored in a refrigerator for $24 \mathrm{~h}$. After $24 \mathrm{~h}$, the sample was centrifuged at $12000 \mathrm{rpm}$ for $10 \mathrm{~min}$. The supernatant was removed, and $500 \mu \mathrm{l}$ of $70 \%$ ethanol was added. The mixture was then centrifuged at $12000 \mathrm{rpm}$ for $5 \mathrm{~min}$. The supernatant was discarded to retain only the pellet. Subsequently, the supernatant was added with $500 \mu \mathrm{l}$ of absolute ethanol and centrifuged at 12 $000 \mathrm{rpm}$ for 5 minutes. The supernatant was discarded, and the pellets were airdried for $24 \mathrm{~h}$ and dissolved with $50 \mu \mathrm{l}$ of aqua-bidest.
Thirteen SSR primers were used for DNA amplification via polymerase chain reaction (PCR). The SSR primers were selected because they were able to characterize the five accessions of tea that were exploited to develop plants with high-quality and high-quantity yield (Azka, 2019) in accordance with the aim of natural crossing. The PCR mixture was divided into $10 \mu \mathrm{l}$ tubes. Each $10 \mu \mathrm{l}$ reaction consisted of $0.25 \mu \mathrm{l}$ of primer, 5 $\mu \mathrm{l}$ of GoTaq Green, $2.25 \mu \mathrm{l}$ of nucleasefree water, and $2.5 \mu \mathrm{l}$ of DNA (quantified by using GeneQuant spectrophotometer). The PCR mix was run on a Bio-Rad T100TM Thermal Cycler. The first heating cycle was carried out at $95{ }^{\circ} \mathrm{C}$ for $30 \mathrm{~s}$ then was followed by 54 cycles of touchdown. Denaturation was performed at $95{ }^{\circ} \mathrm{C}$ for $30 \mathrm{~s}$. All primers were annealed at $60{ }^{\circ} \mathrm{C}, 58^{\circ} \mathrm{C}, 56^{\circ} \mathrm{C}, 54^{\circ} \mathrm{C}$, $52{ }^{\circ} \mathrm{C}$, and $50{ }^{\circ} \mathrm{C}$ (Table 1) for $45 \mathrm{~s}$ at each temperature (touchdown). Elongation was performed at $72{ }^{\circ} \mathrm{C}$ for 1 $\min 30 \mathrm{~s}$. The last cycle was followed by the final elongation cycle at $72{ }^{\circ} \mathrm{C}$ for 30 s. The amplified DNA was visualized by using $2 \%$ MetaPhor agarose gel electrophoresis (MAGE). The 2\% MAGE gel consisted of $0.6 \mathrm{~g}$ of MetaPhor ${ }^{\mathrm{TM}}$ agarose, $30 \mathrm{ml}$ of $1 \times$ Tris-borate-EDTA, and $5 \mu \mathrm{l}$ of FluoroSafe DNA. The MAGE gel was then subjected to horizontal gel electrophoresis (Bio Rad PowerPack Basic ${ }^{\mathrm{TM}}$ ) for 75 min at $100 \mathrm{~V}$ and $400 \mathrm{~mA}$.

\section{Paternity analysis}

Two approaches were used to identify the male parents in the natural hybridization progenies of Assamica. The first approach was based on the putative specific markers of the parents, whereas the second approach comprised the exclusion and likelihood approach. The putative SSR-specific markers in the parental genotypes were identified by looking at the presence and number of polymorphic alleles that were specific to each parent and that can be used to differentiate the parents from one another (Govindaraj et 
Table 1. SSR primers used for the molecular characterization of the tea genotypes.

\begin{tabular}{|c|c|c|c|}
\hline No. & Primers & Primer Sequences (5'-3') & Annealing Temperature $\left({ }^{\circ} \mathrm{C}\right)$ \\
\hline 1. & CamsinM1 & $\begin{array}{l}\text { F: GAATCAGGACATTATAGGAATTAA } \\
\text { R: GGCCGAATGTTGTCTTTTGT }\end{array}$ & $\begin{array}{l}60{ }^{\circ} \mathrm{C}, 58{ }^{\circ} \mathrm{C}, 56{ }^{\circ} \mathrm{C}, 54 \\
{ }^{\circ} \mathrm{C} \text {, and } 52{ }^{\circ} \mathrm{C} \text { (five }\end{array}$ \\
\hline 2. & CamsinM2 & $\begin{array}{l}\text { F: CCTCTGGTGGTCCTACACCT } \\
\text { R: AAAGCCTTGATGCCTTTCG }\end{array}$ & $\begin{array}{l}\text { temperatures for all } \\
\text { primers - Touchdown) }\end{array}$ \\
\hline 3. & CamsinM3 & $\begin{array}{l}\text { F: GGTGTGGTGTTITGAAGAAA } \\
\text { R: TGTTAAGCCGCTTCAATGC }\end{array}$ & \\
\hline 4. & CamsinM5 & $\begin{array}{l}\text { F: AAACTTCAACAACCAGCTCTGGTA } \\
\text { R: ATTATAGGATGCAAACAGGCATGA }\end{array}$ & \\
\hline 5. & CamsinM6 & $\begin{array}{l}\text { F: TGTTTCTTAGGGTTGGATAAAGG } \\
\text { R: TITTGTGTAATGACGAAAATTC }\end{array}$ & \\
\hline 6. & CamsinM7 & $\begin{array}{l}\text { F: TGGTAAGGGTCCTAAGAGGTACAC } \\
\text { R: TTCCAATCTITICTATAACATCTGC }\end{array}$ & \\
\hline 7. & CamsinM8 & $\begin{array}{l}\text { F: CCATCATTGGCCATTACTACAA } \\
\text { R: CCATATGTGTGTGAATGATAAAACC }\end{array}$ & \\
\hline 8. & CamsinM9 & $\begin{array}{l}\text { F: CTCATGGAGTCCAAGGAAGC } \\
\text { R: AAAGCAGTCTGGAACCTTGC }\end{array}$ & \\
\hline 9. & CamsinM10 & $\begin{array}{l}\text { F: TTACATCTCTITGCAGCTGTCGG } \\
\text { R: CTTCGGGAACTTCTGCTICATC }\end{array}$ & \\
\hline 10. & CamsinM11 & $\begin{array}{l}\text { F: GCATCATTCCACCACTCACC } \\
\text { R: GTCATCAAACCAGTGGCTCA }\end{array}$ & \\
\hline 11. & CamsinM12 & $\begin{array}{l}\text { F: CATTATCGTCACTTGCAAAGAGGT } \\
\text { R: CGAGAAGAAGAGCTCTATTGGTT }\end{array}$ & \\
\hline 12. & CamsinM13 & $\begin{array}{l}\text { F: CACATTGTGGCGTGTTATTAATTT } \\
\text { R: ACATTGGCTATCTCTCATCATGG }\end{array}$ & \\
\hline 13. & M4 & $\begin{array}{l}\text { F: ACATTCAAGCAGTCCACATAT } \\
\text { R: CCTGATGCAGGACTGTCTATAGATGA }\end{array}$ & \\
\hline
\end{tabular}

Source: Freeman et al., (2004)

al., 2012). The putative specific alleles in the parental genotypes were used to identify every progeny. All the progeny genotypes were compared with the candidate male parent (PGL-10, GMB-9, GMB-7, TPS-93, GMB-11, and TRI-2025) and female parent (PGL-15) in reference to the Mendelian law for codominant inheritance. The male parent of the $F_{1}$ progeny was selected on the basis of the presence of identical putative specific alleles and the highest allelic similarity percentage.

Paternity analysis through the exclusion and likelihood approach was performed by using Cervus 3.0 software (Kalinowski et al., 2007). The six parental accessions (PGL-10, GMB-9, GMB-7, TPS93, GMB-11, and TRI-2025) were used as the candidate male parents, whereas genotype PGL-15 was used as the female parent. The paternity analysis simulation was run with the likelihood method with the number of progenies, male candidates, the proportion of samples, the proportions of loci types, and mistyping set as $72,6,1.000$ (100\% of sample read), 0.7 ( $70 \%$ of the valid data given that data were missing [0]), and 0.01 ( $99 \%$ confidence interval), respectively. The logarithm of the odds (LOD) value of each possible parent-progeny pair was used to determine the true parent (Jones et al., 2010). A positive LOD score indicates that the parental candidate is the real parent. A zero LOD score (0) indicates that the probability of a candidate parent is the real parent and not the real parent is the same. A negative LOD score indicates that one or more loci of the candidate parent differ from those of the progeny (Kalinowski et al., 2007). The 
critical LOD scores with $95 \%$ and $80 \%$ levels of confidence were calculated on the basis of the simulation analysis. In the paternity analysis, the level of confidence for each candidate male parent was determined by using the trio confident scores. If the trio confidence scores are followed by the symbol $(*)$, then the confidence is 95\%; if the values are positive but are not followed by the symbol $(*)$, then the confidence is $80 \%$; negative scores have less than $80 \%$ confidence (Kalinowski et al., 2007).

\section{RESULTS}

\section{Parentage analysis based on putative specific alleles}

In this study, 13 SSR loci (Table 1) were used to identify the male parents of the $F_{1}$ progenies obtained through natural hybridization between PGL-15 (female) and six male tea accessions of Assamica (PGL-10, GMB-9, GMB-7, TPS-93, GMB11 , and TRI-2025) in the Kayulandak second polyclonal seed garden of PT Pagilaran. The seven candidate parent accessions involved in natural hybridization had a fairly high percentage of allele similarities between accessions with an average of $67.85 \%$ (Table 2). Among individual pairs, the tea genotypes that exhibited the highest percentage of allele similarity (88.24\%) were TRI-2025 and PGL-10. The highest level of similarity between these genotypes could be attributed to the fact that PGL-10 was obtained from a half-sibling progeny population selection with TRI-2025 as the female parent (Decree of the Agriculture Minister of the Republic of Indonesia No. 51/Kpts/KB.010/3/2020). The Decree of the Agriculture Minister of Republic of Indonesia No. 26/Kpts/KB.010/3/2020 regarding the release of tea accession PGL-15 as a superior cultivar stated that similar to PGL-10, PGL-15 was also obtained from half-sibling progeny population selection with TRI-2025 as the female parent. By using RAPD markers, Ramakrishnan et al. (2009) classified the tea accession TRI-2025 as the 'Cambod' cultivar (C. assamica subspecies lasiocalyx). The 'Cambod' cultivar is a hybrid of sinensis and assamica cultivars (Wambulwa et al., 2016). Accessions GMB-7 and GMB-11 were $F_{1}$ hybrids that were obtained from the crosses of the parental genotypes Mal-2 and PS-1, whereas the $F_{1}$ hybrid GMB-9 was obtained from the genotypes GP-3 and PS-1.

Furthermore, specific markers were estimated on the basis of the seven parental accessions by using 13 SSR loci. A specific marker or allele for each accession was identified by determining the unique bands that were found only in one accession and not in other accessions. A previous study revealed that among seven parental accessions, putative specific markers were recorded for only three accessions, namely, PGL-15, GBM-7, and GBM-9, (Nisa, 2020) (Table 3). The female tea parent PGL-15 was characterized by four putative specific loci,

Table 2. Allele similarity (above diagonal) and dissimilarity (below diagonal) percentage between the parental accessions of the tea genotypes.

\begin{tabular}{llllllll}
\hline Parental accessions & PGL15 & TPS93 & GMB7 & GMB9 & GMB11 & PGL10 & TRI2025 \\
\hline PGL15 & - & 66.67 & 66.67 & 61.11 & 57.89 & 64.71 & 64.71 \\
TPS93 & 33.33 & - & 72.22 & 66.67 & 68.42 & 76.47 & 64.71 \\
GMB7 & 33.33 & 27.78 & - & 61.11 & 68.42 & 58.82 & 64.71 \\
GMB9 & 38.89 & 33.33 & 38.89 & - & 68.42 & 70.59 & 70.59 \\
GMB11 & 42.11 & 31.58 & 31.58 & 31.58 & - & 76.47 & 88.24 \\
PGL10 & 35.29 & 23.53 & 41.18 & 29.41 & 23.53 & - & 88.24 \\
TRI2025 & 35.29 & 35.29 & 35.29 & 29.41 & 11.76 & 11.76 & - \\
\hline Average similarity & $67.85 \%$ & & & & & & \\
\hline
\end{tabular}


Table 3. Putative specific alleles in the parental accessions of tea.

\begin{tabular}{lll}
\hline Accessions & Loci & Putative Specific Allele (bp) \\
\hline & Camsin M3 & 230 \\
PGL-15 & M4c & 330 \\
& Camsin M5 & 180 \\
& Camsin M7 & 220 \\
\hline TPS 93 & - & None \\
\hline GMB 7 & Camsin M8 & 140 \\
\hline & Camsin M6 & 270 \\
GMB 9 & Camsin M8 & 170 \\
& Camsin M9 & 210 \\
\hline GMB 11 & Camsin M11 & 190 \\
PGL-10 & - & None \\
TRI 2025 & - & None \\
\hline
\end{tabular}

Source: Nisa (2020)

i.e., the 230-bp Camsin M3 allele, the 330-bp M4c allele, the 180-bp Camsin M5 allele, and the 220-bp Camsin M7 allele. The male parental accession GMB-7 was characterized by one putative specific locus on the 140-bp Camsin M8 allele. The male parent accession GMB-9 was characterized by four specific loci on the 270-bp Camsin M6 allele, the 170-bp Camsin M8 allele, the 210-bp Camsin M9 allele, and the 190-bp Camsin M11 allele.

The presence of putative specific markers in the three parental accessions was then used to predict the male genotypes on the basis of the presence of that specific allele in each progeny by using the Mendelian law for codominant inheritance. In this case, the parental accessions that did not show a putative specific allele cannot be used to predict the male parents. Therefore, only two male parents were available for paternity analysis, i.e., GMB-7 and GMB-9, and PGL-15 was considered as the female parent.

Male parent determination was based on the presence of putative specific alleles in the progeny. If more than one putative specific allele in the progeny was obtained from different candidate male parents, the male parent prediction was based on the largest percentage of allelic similarities between the progeny and the candidate male parent. The largest percentage of allelic similarities between the progeny and candidate male parent implies a high probability of being the true pollen parent (Norman et al., 2018). On the basis of the results, the putative specific alleles can be used to predict the male parents of 25 progenies. The male parents were GMB-7 and GMB-9 (Table 4).

\section{Parentage analysis by using the exclusion and likelihood approach}

The second paternity analysis was performed through the exclusion and likelihood approach by using Cervus 3.0 software. Exclusion and likelihood analysis was used to compare the candidate parental genotypes with their $F_{1}$ progenies. Parental genotypes that had one or more different loci from their progeny were then excluded as candidate parents. The likelihood in this program was used to distinguish nonexcluded candidate parents (Kalinowski et al., 2007).

The exclusion and likelihood method was able to predict the male parents of all the 72 progenies. Ten male parent-progeny pairs were identified with a $95 \%$ level of confidence: GMB-7-01.10, GMB-9-02.7, GMB-7-02.13-, TPS-9302.16, TRI-2025-03.2, GMB-7-03.20, 
Table 4. Parentage analysis based on putative specific alleles in the tea genotypes.

\begin{tabular}{|c|c|c|c|c|c|c|c|c|c|c|c|}
\hline \multirow[b]{2}{*}{$\begin{array}{l}\text { Progen } \\
\text { y ID }\end{array}$} & \multicolumn{2}{|c|}{ GMB7 } & \multicolumn{2}{|c|}{ GMB9 } & \multirow[b]{2}{*}{$\begin{array}{l}\text { Expected } \\
\text { Father }\end{array}$} & \multirow[b]{2}{*}{ Progeny } & \multicolumn{2}{|c|}{ GMB7 } & \multicolumn{2}{|c|}{ GMB9 } & \multirow[b]{2}{*}{$\begin{array}{l}\text { Expected } \\
\text { Father }\end{array}$} \\
\hline & $\begin{array}{l}\text { Allele } \\
\text { Similarity } \\
\%\end{array}$ & $\begin{array}{l}\text { Specific } \\
\text { Allele }\end{array}$ & $\begin{array}{l}\text { Allele } \\
\text { Similarity } \\
\%\end{array}$ & Specific Allele & & & $\begin{array}{l}\text { Allele } \\
\text { Similarity } \\
\%\end{array}$ & $\begin{array}{l}\text { Specific } \\
\text { Allele }\end{array}$ & $\begin{array}{l}\text { Allele } \\
\text { Similarity } \\
\%\end{array}$ & $\begin{array}{l}\text { Specific } \\
\text { Allele }\end{array}$ & \\
\hline 01.1 & 22.22 & None & 27.78 & None & Unknown & 02.18 & 16.67 & None & 22.22 & M11-190 & GMB9 \\
\hline 01.2 & 11.11 & None & 16.67 & None & Unknown & 02.19 & 16.67 & None & 22.22 & M6-270 & GMB9 \\
\hline 01.3 & 16.67 & M7-190 & 16.67 & M6-270 & GMB7, GMB9 & 03.1 & 5.56 & None & 5.56 & None & Unknown \\
\hline 01.4 & 11.11 & None & 16.67 & None & Unknown & 03.2 & 11.11 & None & 27.78 & M6-270 & GMB9 \\
\hline 01.5 & 16.67 & M8-140 & 11.11 & None & Unknown & 03.3 & 0.00 & None & 5.56 & None & Unknown \\
\hline 01.6 & 5.56 & None & 11.11 & None & Unknown & 03.6 & 11.11 & None & 11.11 & None & Unknown \\
\hline 01.7 & 16.67 & None & 22.22 & None & Unknown & 03.7 & 16.67 & None & 5.56 & None & Unknown \\
\hline 01.8 & 11.11 & M8-140 & 11.11 & M8-170 & GMB7, GMB9 & 03.9 & 11.11 & M7-190 & 11.11 & None & GMB7 \\
\hline 01.9 & 5.56 & None & 16.67 & M8-170 & GMB9 & 03.10 & 11.11 & None & 16.67 & M11-190 & GMB9 \\
\hline 01.10 & 27.78 & M8-140 & 16.67 & None & GMB7 & 03.11 & 22.22 & M7-190 & 11.11 & None & GMB7 \\
\hline 01.11 & 11.11 & None & 5.56 & None & Unknown & 03.12 & 11.11 & None & 11.11 & None & Unknown \\
\hline 01.12 & 11.11 & M8-140 & 11.11 & None & GMB7 & 03.13 & 11.11 & None & 16.67 & None & Unknown \\
\hline 01.14 & 5.56 & None & 0.00 & None & Unknown & O3.14 & 5.56 & None & 0.00 & None & Unknown \\
\hline 01.15 & 0.00 & None & 0.00 & None & Unknown & 03.16 & 5.56 & None & 5.56 & None & Unknown \\
\hline 01.16 & 0.00 & None & 5.56 & None & Unknown & 03.17 & 5.56 & None & 0.00 & None & Unknown \\
\hline 01.17 & 11.11 & None & 11.11 & None & Unknown & 03.18 & 16.67 & None & 5.56 & None & Unknown \\
\hline 01.18 & 5.56 & None & 11.11 & None & Unknown & 03.19 & 0.00 & None & 5.56 & M6-270 & GMB9 \\
\hline 01.19 & 22.22 & M8-140 & 16.67 & None & GMB7 & 03.20 & 27.78 & None & 27.78 & M9-210 & GMB9 \\
\hline 01.20 & 0.00 & None & 5.56 & None & Unknown & 04.1 & 11.11 & None & 11.11 & None & Unknown \\
\hline 02.1 & 11.11 & None & 11.11 & None & Unknown & 04.2 & 22.22 & None & 16.67 & None & Unknown \\
\hline $\mathrm{O} 2.2$ & 11.11 & None & 0.00 & None & Unknown & 04.3 & 22.22 & None & 11.11 & None & Unknown \\
\hline 02.3 & 16.67 & None & 11.11 & None & Unknown & 04.4 & 5.56 & None & 22.22 & M11-190 & GMB9 \\
\hline $\mathrm{O} 2.4$ & 0.00 & None & 5.56 & None & Unknown & 04.5 & 5.56 & None & 5.56 & None & Unknown \\
\hline 02.5 & 11.11 & None & 11.11 & None & Unknown & 04.6 & 5.56 & M8-140 & 11.11 & M6-270 & $\begin{array}{l}\text { GMB7, } \\
\text { GMB9 }\end{array}$ \\
\hline 02.6 & 11.11 & None & 16.67 & None & Unknown & 04.7 & 11.11 & M8-140 & 0.00 & None & GMB7 \\
\hline 02.7 & 16.67 & None & 33.33 & M8-170 & GMB9 & 04.8 & 11.11 & M8-140 & 0.00 & None & GMB7 \\
\hline 02.8 & 11.11 & None & 0.00 & None & Unknown & 04.9 & 0.00 & None & 11.11 & M8-170 & GMB9 \\
\hline 02.9 & 11.11 & None & 5.56 & None & Unknown & 04.10 & 5.56 & None & 16.67 & M6-270 & GMB9 \\
\hline 02.10 & 0.00 & None & 5.56 & None & Unknown & 04.11 & 5.56 & None & 16.67 & None & Unknown \\
\hline 02.11 & 5.56 & None & 11.11 & None & Unknown & 04.12 & 11.11 & None & 16.67 & None & Unknown \\
\hline 02.12 & 11.11 & M7-190 & 11.11 & None & GMB7 & 04.13 & 11.11 & None & 11.11 & None & Unknown \\
\hline 02.13 & 22.22 & $\begin{array}{l}\text { M8-140, M7- } \\
190\end{array}$ & 11.11 & M6-270 & GMB7, GMB9 & 04.14 & 5.56 & None & 11.11 & None & Unknown \\
\hline 02.14 & 5.56 & None & 5.56 & None & Unknown & 04.15 & 11.11 & None & 5.56 & M8-170 & GMB9 \\
\hline 02.15 & 16.67 & None & 11.11 & None & Unknown & 04.16 & 16.67 & None & 22.22 & None & Unknown \\
\hline 02.16 & 16.67 & None & 22.22 & None & Unknown & 04.17 & 16.67 & None & 27.78 & M8-170 & GMB9 \\
\hline 02.17 & 5.56 & None & 5.56 & None & Unknown & 04.18 & 5.56 & None & 16.67 & None & Unknown \\
\hline
\end{tabular}


Table 5. Parentage analysis using the exclusion and likelihood method (progenies 01.1-02.19) in the tea genotypes.

\begin{tabular}{|c|c|c|c|c|c|c|c|c|c|c|c|}
\hline $\begin{array}{l}\text { Progen } \\
\text { y ID }\end{array}$ & $\begin{array}{l}\text { Mother } \\
\text { ID }\end{array}$ & $\begin{array}{l}\text { Candidate } \\
\text { father ID }\end{array}$ & $\begin{array}{c}\text { Trio loci } \\
\text { mis- } \\
\text { matching }\end{array}$ & $\begin{array}{l}\text { Trio } \\
\text { score }\end{array}$ & $\begin{array}{c}\text { Trio } \\
\text { confidenc } \\
\mathrm{e}\end{array}$ & $\begin{array}{l}\text { Proge } \\
\text { ny ID }\end{array}$ & $\begin{array}{l}\text { Mother } \\
\text { ID }\end{array}$ & $\begin{array}{l}\text { Candidate } \\
\text { father ID }\end{array}$ & $\begin{array}{c}\text { Trio loci } \\
\text { mis- } \\
\text { matching }\end{array}$ & $\begin{array}{l}\text { Trio LOD } \\
\text { score }\end{array}$ & $\begin{array}{c}\text { Trio } \\
\text { confide } \\
\text { nce }\end{array}$ \\
\hline 04.1 & PGL15 & GMB7 & 9 & $-6.13 E+00$ & - & 02.3 & PGL15 & GMB7 & 8 & $-2.24 \mathrm{E}+00$ & - \\
\hline 04.2 & PGL15 & GMB7 & 8 & 1.19E+00 & $*$ & 02.4 & PGL15 & TRI2025 & 10 & $-4.00 E+00$ & - \\
\hline 04.3 & PGL15 & GMB11 & 10 & $5.20 E-01$ & $*$ & 02.5 & PGL15 & PGL10 & 10 & $-1.07 E+01$ & - \\
\hline 04.4 & PGL15 & GMB9 & 8 & $-1.61 \mathrm{E}-01$ & - & 02.5 & PGL15 & TRI2025 & 10 & $-1.07 E+01$ & - \\
\hline 04.5 & PGL15 & TPS93 & 9 & $-8.77 E+00$ & - & 02.6 & PGL15 & PGL10 & 9 & $-1.30 E+00$ & - \\
\hline 04.6 & PGL15 & GMB9 & 11 & $-3.92 E+00$ & - & 02.7 & PGL15 & GMB9 & 8 & $2.28 \mathrm{E}+00$ & $*$ \\
\hline 04.7 & PGL15 & GMB7 & 11 & $-4.39 E+00$ & - & 02.8 & PGL15 & GMB7 & 9 & $-3.77 E+00$ & - \\
\hline 04.8 & PGL15 & GMB7 & 11 & $-4.39 E+00$ & - & 02.9 & PGL15 & GMB7 & 9 & $-3.97 E+00$ & - \\
\hline 04.9 & PGL15 & TRI2025 & 11 & $-4.68 E+00$ & - & 02.10 & PGL15 & PGL10 & 11 & $-6.26 \mathrm{E}+00$ & - \\
\hline 04.10 & PGL15 & GMB9 & 12 & $-7.42 E+00$ & - & 02.10 & PGL15 & TRI2025 & 11 & $-6.26 \mathrm{E}+00$ & - \\
\hline 04.11 & PGL15 & PGL10 & 9 & $-1.08 E+00$ & - & 02.11 & PGL15 & TPS93 & 10 & $-7.06 E+00$ & - \\
\hline 04.12 & PGL15 & GMB11 & 7 & $3.02 E-01$ & $*$ & 02.12 & PGL15 & PGL10 & 9 & $-3.56 \mathrm{E}+00$ & - \\
\hline 04.13 & PGL15 & GMB11 & 10 & $-8.90 E-01$ & - & 02.12 & PGL15 & TRI2025 & 9 & $-3.56 E+00$ & - \\
\hline 04.14 & PGL15 & TRI2025 & 8 & $-4.79 E+00$ & - & 02.13 & PGL15 & GMB7 & 10 & $3.88 \mathrm{E}-01$ & $*$ \\
\hline 04.15 & PGL15 & GMB7 & 10 & $-8.16 \mathrm{E}+00$ & - & 02.14 & PGL15 & GMB11 & 10 & $-2.32 E+00$ & - \\
\hline 04.16 & PGL15 & PGL10 & 7 & $-4.18 \mathrm{E}+00$ & - & 02.15 & PGL15 & TPS93 & 9 & $-1.34 \mathrm{E}+00$ & - \\
\hline O4.17 & PGL15 & GMB11 & 8 & $6.14 \mathrm{E}-01$ & $*$ & 02.16 & PGL15 & TPS93 & 7 & $1.27 \mathrm{E}+00$ & $*$ \\
\hline 04.18 & PGL15 & TRI2025 & 9 & $-9.68 \mathrm{E}-01$ & - & 02.17 & PGL15 & TPS93 & 11 & $-4.49 E+00$ & - \\
\hline $\mathrm{O} 2.1$ & PGL15 & PGL10 & 9 & $-7.37 E+00$ & - & 02.18 & PGL15 & GMB11 & 8 & $7.30 \mathrm{E}-01$ & - \\
\hline 02.1 & PGL15 & TRI2025 & 9 & $-7.37 E+00$ & - & 02.18 & PGL15 & PGL10 & 8 & $7.30 \mathrm{E}-01$ & - \\
\hline 02.2 & PGL15 & GMB7 & 9 & $-3.77 E+00$ & - & 02.19 & PGL15 & GMB11 & 11 & $-4.71 E+00$ & - \\
\hline
\end{tabular}

*: $95 \%$ level of confidence 
Table 6. Parentage analysis using the exclusion and likelihood method (progenies 03.1-01.20) in the tea genotypes.

\begin{tabular}{|c|c|c|c|c|c|c|c|c|c|c|c|}
\hline $\begin{array}{l}\text { Progen } \\
\text { y ID }\end{array}$ & $\begin{array}{l}\text { Mother } \\
\text { ID }\end{array}$ & $\begin{array}{l}\text { Candidate } \\
\text { father ID }\end{array}$ & $\begin{array}{c}\text { Trio loci } \\
\text { mismatchi } \\
\text { ng }\end{array}$ & Trio LOD score & $\begin{array}{c}\text { Trio } \\
\text { confidence }\end{array}$ & $\begin{array}{l}\text { Progen } \\
\text { y ID }\end{array}$ & $\begin{array}{l}\text { Mother } \\
\text { ID }\end{array}$ & $\begin{array}{l}\text { Candidate } \\
\text { father ID }\end{array}$ & $\begin{array}{c}\text { Trio loci } \\
\text { mis- } \\
\text { matching }\end{array}$ & Trio LOD score & $\begin{array}{c}\text { Trio } \\
\text { confide } \\
\text { nce }\end{array}$ \\
\hline 03.1 & PGL15 & TRI2025 & 11 & $-8.62 \mathrm{E}+00$ & - & 01.4 & PGL15 & GMB11 & 8 & $-5.73 E+00$ & - \\
\hline 03.2 & PGL15 & TRI2025 & 9 & $3.54 \mathrm{E}-01$ & $*$ & 01.4 & PGL15 & PGL10 & 8 & $-5.73 E+00$ & - \\
\hline 03.3 & PGL15 & TPS93 & 11 & $-4.59 E+00$ & - & 01.5 & PGL15 & GMB7 & 10 & $-6.61 \mathrm{E}+00$ & - \\
\hline 03.6 & PGL15 & TPS93 & 9 & $-1.77 E+00$ & - & 01.6 & PGL15 & PGL10 & 8 & $-3.23 E+00$ & - \\
\hline 03.7 & PGL15 & GMB7 & 11 & $-2.62 \mathrm{E}+00$ & - & 01.6 & PGL15 & TRI2025 & 8 & $-3.23 E+00$ & - \\
\hline 03.9 & PGL15 & PGL10 & 10 & $-4.88 E+00$ & - & 01.7 & PGL15 & PGL10 & 7 & $-2.01 \mathrm{E}-01$ & - \\
\hline 03.9 & PGL15 & TRI2025 & 10 & $-4.88 E+00$ & - & 01.7 & PGL15 & TRI2025 & 7 & $-2.01 E-01$ & - \\
\hline 03.10 & PGL15 & TPS93 & 9 & $-1.77 E+00$ & - & 01.8 & PGL15 & PGL10 & 8 & $-2.81 \mathrm{E}+00$ & - \\
\hline 03.11 & PGL15 & GMB7 & 11 & $-9.77 E-01$ & - & 01.8 & PGL15 & TRI2025 & 8 & $-2.81 E+00$ & - \\
\hline 03.12 & PGL15 & TPS93 & 9 & $-5.43 \mathrm{E}-01$ & - & 01.9 & PGL15 & PGL10 & 8 & $-1.82 \mathrm{E}+00$ & - \\
\hline 03.13 & PGL15 & TPS93 & 9 & $-2.29 E+00$ & - & 01.10 & PGL15 & GMB7 & 8 & $2.72 E+00$ & $*$ \\
\hline 03.14 & PGL15 & GMB11 & 12 & $-5.03 E+00$ & - & 01.11 & PGL15 & TPS93 & 10 & $-4.55 E+00$ & - \\
\hline 03.16 & PGL15 & GMB11 & 11 & $-8.05 E+00$ & - & 01.12 & PGL15 & PGL10 & 8 & $-3.52 E+00$ & - \\
\hline 03.16 & PGL15 & TRI2025 & 11 & $-8.05 E+00$ & - & 01.12 & PGL15 & TRI2025 & 8 & $-3.52 \mathrm{E}+00$ & - \\
\hline 03.17 & PGL15 & GMB7 & 11 & $-1.04 \mathrm{E}+01$ & - & 01.14 & PGL15 & TPS93 & 10 & $-5.25 E+00$ & - \\
\hline 03.18 & PGL15 & GMB7 & 9 & $-6.22 E+00$ & - & 01.14 & PGL15 & GMB7 & 10 & $-5.25 E+00$ & - \\
\hline 03.19 & PGL15 & GMB9 & 11 & $-5.42 E+00$ & - & 01.14 & PGL15 & GMB11 & 10 & $-5.25 E+00$ & - \\
\hline 03.20 & PGL15 & GMB7 & 8 & $2.63 E+00$ & $*$ & 01.15 & PGL15 & TRI2025 & 11 & $-5.53 E+00$ & - \\
\hline 01.1 & PGL15 & TPS93 & 7 & $-1.07 E+00$ & - & 01.16 & PGL15 & TRI2025 & 9 & $-2.97 E+00$ & - \\
\hline 01.2 & PGL15 & TPS93 & 10 & $1.31 \mathrm{E}-01$ & - & 01.17 & PGL15 & TPS93 & 9 & $-7.14 \mathrm{E}+00$ & - \\
\hline 01.2 & PGL15 & PGL10 & 10 & $1.31 \mathrm{E}-01$ & - & 0.18 & PGL15 & GMB11 & 10 & $-5.02 E+00$ & - \\
\hline 01.3 & PGL15 & GMB7 & 10 & $-6.72 E+00$ & - & 01.19 & PGL15 & TRI2025 & 9 & $-3.48 E+00$ & - \\
\hline 01.4 & PGL15 & TPS93 & 8 & $-5.73 E+00$ & - & 01.20 & PGL15 & GMB9 & 11 & $-9.25 E+00$ & - \\
\hline 01.4 & PGL15 & GMB9 & 8 & $-5.73 E+00$ & - & 01.20 & PGL15 & GMB11 & 11 & $-9.25 E+00$ & - \\
\hline
\end{tabular}

*: $95 \%$ level of confidence

Table 7. Matching results of the parentage analysis based on the specific putative allele and exclusion-likelihood approach in the tea genotypes.

\begin{tabular}{|c|c|c|c|c|c|c|c|c|c|}
\hline \multirow{3}{*}{ Progeny } & \multicolumn{5}{|c|}{ Parentage based on putative specific allele } & \multirow{3}{*}{$\begin{array}{l}\text { Progeny } \\
\text { ID }\end{array}$} & \multicolumn{3}{|c|}{ Parentage based on the exclude and likelihood method } \\
\hline & \multicolumn{2}{|c|}{ GMB7 } & \multicolumn{2}{|l|}{ GMB9 } & \multirow[b]{2}{*}{ Expected male } & & \multirow[b]{2}{*}{ Candidate male ID } & \multirow[b]{2}{*}{ Trio LOD score } & \multirow{2}{*}{$\begin{array}{l}\text { Trio } \\
\text { confidence }\end{array}$} \\
\hline & $\begin{array}{l}\text { Allele } \\
\text { similarity (\%) }\end{array}$ & $\begin{array}{l}\text { Specific } \\
\text { allele }\end{array}$ & $\begin{array}{l}\text { Allele } \\
\text { similarity (\%) }\end{array}$ & $\begin{array}{l}\text { Specific } \\
\text { allele }\end{array}$ & & & & & \\
\hline Seedling 4.7 & 11.11 & M8-140 & 0 & - & GMB7 & 04.7 & GMB7 & $-4.39 \mathrm{E}+00$ & - \\
\hline Seedling 4.8 & 11.11 & M8-140 & 0 & - & GMB7 & 04.8 & GMB7 & $-4.39 E+00$ & - \\
\hline Seedling 4.10 & 5.56 & - & 16.67 & M6-270 & GMB9 & 04.10 & GMB9 & $-7.42 E+00$ & - \\
\hline Seedling 2.7 & 16.67 & - & 33.33 & M8-170 & GMB9 & 02.7 & GMB9 & $2.28 \mathrm{E}+00$ & $*$ \\
\hline Seedling 2.13 & 22.22 & $\begin{array}{l}\text { M8-140, } \\
\text { M7-190 }\end{array}$ & 11.11 & M6-270 & GMB7, GMB9 & 02.13 & GMB7 & $3.88 \mathrm{E}-01$ & $*$ \\
\hline Seedling 3.11 & 22.22 & M7-190 & 11.11 & - & GMB7 & 03.11 & GMB7 & $-9.77 \mathrm{E}-01$ & - \\
\hline
\end{tabular}


GMB-7-04.2, GMB-11-04.3, GMB-1104.12, and GMB-11-04.17 (Tables 5 and 6 ). The results also revealed several male parent-progeny pairs with positive LOD scores that were not followed by the symbol $(*)$. This result indicated that the said pairs had an $80 \%$ level of confidence, whereas those with negative LOD scores had less than an $80 \%$ level of confidence (Kalinowski et al., 2007).

\section{DISCUSSION}

The transcriptomic analysis of the stylus after self and cross-pollination revealed that tea plants exhibit gametophytic selfincompatibility because they have gametophytic pollens (Zhang et al., 2016). Complete pollination can be successful only if the alleles in the pollen and pistil are different from each other (Chahal and Gosal, 2002). Crosspollination results in generatively propagated tea with the highest heterogeneity, and natural hybridization can be exploited to develop high-yielding tea cultivars. Specific progenies produced through natural crosses at the Kayulandak second polyclonal seed garden of PT Pagilaran were used in this study.

Paternity analysis based on putative specific alleles predicted 25 male parent-progeny pairs because only three accessions exhibited putative specific alleles, i.e., PGL-15, GMB-7, and GMB-9, whereas the genotype PGL-15 was considered the female parent. Therefore, to increase the level of accuracy in paternity analysis, the data were also analyzed through the exclusion and likelihood method by using Cervus 3.0 software. The exclusion and likelihood approach was able to predict the male parents of 72 progenies with more than $95 \%$ level of confidence for 10 male parent-progeny pairs and $80 \%$ level of confidence or less for the remaining pairs. The comparison of paternity analyses based on the putative specific alleles and exclusion-likelihood approach revealed similarities in the estimation for six male parent-progeny pairs, namely, GMB-9-
O2.7, GMB-7-02.13, GMB-7-03.11, GMB7-04.7, GMB-7-04.8, and GMB-9-04.10 (Table 7).

The paternity analysis using the putative specific allele method revealed that the male parent-progeny allele similarity was relatively low with an average of $11.38 \%$, whereas the exclusion-likelihood method identified numerous mismatched loci likely as a result of several factors, including a limited number of parent accessions used in this study, and some progenies had alleles that could not be found in the female or male parent genotype. As observed by other researchers, the contribution of the shared and unshared parents cannot be unambiguously determined if the shared parent and one of its progeny have the same heterozygous genotype (Fiumera and Asmussen, 2001). Therefore, distinct parental candidates are required for accurate paternity analysis.

Pollinator involvement may also increase the occurrence of crosspollination. Pollinators, such as flies (Diptera spp.) and bees, can carry pollen from relatively long distances for crosspollination in tea plants (Mitra et al., 2017). The amount of pollen that is carried by the insect and deposited on the stigma may be influenced by the spatial isolation and population size that may reduce the pollinator visitation frequency in tristylous populations (Hodgins and Barret, 2006). A previous study showed that the fitness of $C$. sinensis pollen with respect to the germination ability varies due to many factors, such as pollen shedding duration, and environmental factors, such as temperature and rainfall (Muoki et al., 2007). Another factor that may play a significant role in low parentprogeny allelic similarity was the limited number of genetic markers used in this study because for successful paternity analysis, highly polymorphic markers are required (Jones et al., 2010). Therefore, the use of a very large number of markers with a high level of polymorphism is recommended for successful parentage analysis. 


\section{CONCLUSIONS}

The results showed that the exclusionlikelihood approach was more effective than the putative specific allele method in the prediction of the male parents of $F_{1}$ tea progenies. The exclusion-likelihood method predicted $100 \%$ of the male parents, whereas the putative specific allele method predicted $34.72 \%$ of the male parents in 72 hybridized $F_{1}$ progenies.

\section{ACKNOWLEDGEMENTS}

We would like to thank the Ministry of Research, Technology, and Higher Education, Republic of Indonesia (KEMRISTEKDIKTI) for funding this study.

\section{REFERENCES}

Akula A, Akula C (1999) Somatic Embryogenesis in Tea (Camellia sinensis (L.) O. Kuntze). In: Jain SM, Gupta PK, Newton RJ (eds) Somatic Embryogenesis in Woody Plants. Forestry Sciences, vol. 59. Springer, Dordrecht.

https://doi.org/10.1007/978-94-0114774-3_15.

Azka NA, Widhianata H, Taryono (2019) Morphological and molecular characterization of 5 accessins of tea (Camellia sinensis (L.) O. Kuntze) exploited to develop high quality and quantity yield. $1^{\text {st }}$ International Conference on Bioinformatics, Biotechnology, and Biomedical Engineering (Biomic 2018). AIP Conf. Proc. 2099. https://doi.org/10.1063/1.5098408 .

Bandyopadhyay T (2011). Molecular marker technology in genetic improvement of tea. Int, J. Plant Breed. Genet. 5: 2333.

Buteler MI, LaBonte DR (2002) Microsatellitebased paternity analysis in polyploidy sweetpotato. J. Amer. Soc. Hort. Sci. 127(3): 392-396.

Chahal GS, Gosal SS (2002). Principles and Procedures of Plant Breeding: Biotechnological and Conventional Approaches. Alpha Sci. Int. Ltd., UK.
Chen D, Milacic V, Chen MS, Wan SB, Lam WH, Huo C, Landis-Piwowar KR, Cui QC, Wali A, Chan TH, Ping Q (2008). Tea polyphenols, their biological effects and potential molecular targets. Histol. Histopathol. 23(4): 487-96.

Diaz A, Martin A, Rallo P, Barranco D, De-laRosa R (2006). Self-incompatibility of Arbequina and Picual olive assessed by SSR markers. J. Am. Soc. Hort. Sci. 131: 250-255.

Doyle JJ, Doyle JL (1990). Isolation of plant DNA from fresh tissue. Focus 12: 1315.

Fan $F Y$, Yan DH, Borthakur D, Liang YR, Luo XY, Wei J, Liu SC, Lu JL (2011). Application of molecular tools in parentage identification and gene diversity study in tea (Camellia sinensis) germplasm of Guizhou province, China. Two and a Bud 58: 39-43.

Fiumera AC, Asmussen MA (2001). Difficulties in parentage analysis: the probability that an offspring and parent have the same heterozygous genotype. Genet. Res. Camb. 78: 163-170.

Freeman S, West J, James C, Lea V, Mayes S (2004). Isolation and characterization of highly polymorphic microsatellites in tea (Camellia sinensis). Mol. Ecol. Notes 4: 324-326.

Gjedrem T (2010) The first family-based breeding program in aquaculture. Rev. Aquac. 2:2-15.

Govindaraj P, Balamurugan A, Natarajam US (2012). Identification of intergenic hybrid between Erianthus arundinaceus and Saccharum spontaneum through STMS markers. Int. Sugar J. 114: 350356.

Hodgins KA, Barrett SCH (2006). Female reproductive success and the evolution of mating-type frequencies in tristylous populations. New Phytol. 171: 569580.

Jones AG, Ardren WR (2003). Methods of parentage analysis in natural populations. Mol. Ecol. 12: 2511-2523.

Jones AG, Small CM, Paczolt KA, Ratterman NL (2010). A practical guide to methods of parentage analysis. Mol. Ecol. Resour. 10: $6-30$

Kalinowski ST, Taper ML, Marshall TC (2007). Revising how the computer program CERVUS accommodates genotyping error increases success in paternity assignment. Mol. Ecol. 16: 1099-1106. 
Kottawa-Arachchi JD, Gunasekare MTK, Ranatunga MAB (2019). Biochemical diversity of global tea [Camellia sinensis (L.) O. Kuntze] germplasm and its exploitation: A Review. Genet. Resour. Crop Evol. 66: 259-273.

Mitra B, Roy S, Shah SK, Mishra P (2017). Inventorisation of true flies (Insecta: Diptera) and their association with tea plants in Dooars, West Bengal, India. Int. J. Entomol. Res. 2: 21-26.

Mookerjee S, Guerin J, Collins G, Ford C, Sedgley M (2005). Paternity analysis using microsatellite markers to identify pollen donors in an olive grove. Theor. Appl. Genet. 111: 1174-1182.

Muoki CR, Wachira FN, Pathak RS, Kamunya SM (2007) Assessment of the mating system of Camellia sinensis in biclonal seed orchards based on PCR markers. J. Hort. Sci. Biotechnol. 82(5):733738.

Navascues M, Emerson BC (2005) Chloroplast microsatellites: Measures of genetic diversity and the effect of homoplasy. Mol. Ecol. 14(5):1333-13341.

Nisa, YS (2020) Morphological and SSR characterization of tea accessions (Camellia Sinensis (L.) O. Kuntze) in Kayulandak Polyclonal Garden of PT Pagilaran. Manuscript in preparation.

Norman PE, Asfaw A, Tongoona PB, Danquah A, Danquah EY, Koeyer DD, Asiedu R (2018) Can parentage analysis facilitate breeding activities in root and tuber crops? MDPI J. Agric. 95(8):1-24.

Ramakrishnan M, Rajanna L, Papanna N, Simon L (2009). Assessment of genetic relationship and hybrid evaluation studies in tea (Camellia sp.) by RAPD. Int. J. Plant Breed. 3: 144-148.

Spanoghe M, Marique T, Riviere J, Lanterbecq D, Gadenne M (2015). Investigation and development of potato parentage analysis methods using multiplexed SSR fingerprinting. Potato Res. 58:4365.

Thongthawae S, Tittinutchanon P, Volkaert $\mathrm{H}$ (2010) Microsatellites for parentage analysis in an oil palm breeding population. Thai Journal of Genetics 3(2):172-181.

Vieira MLC, Santini L, Diniz AL, Munhoz CF (2016). Microsatellite markers: what they mean and why they are so useful. Genet. Mol. Biol. 39: 312-328.

Wambulwa MC, Meegahakumbura MK, Chalo R, Kamunya S, Muchugi A, Xu J (2016). Nuclear microsatellites reveal the genetic architecture and breeding history of tea germplasm of East Africa. Tree Genet. Genomes 12: 11. https://doi.org/10.1007/s11295-0150963-x

Yamamoto T, Mochida K, Imai T, Shi $\mathrm{YZ}$, Ogiwara I, Hayashi T (2002). Microsatellite markers in peach (Prunus persica (L.) Batsch) derived from an enriched genomic and cDNA library. Mol. Ecol. Notes 2: 298-301.

Zhang CC, Wang LY, Wei K, Wu LY, Li HL, Zhang $F$, Cheng $H$, Li DJ (2016). Transcriptome analysis reveals selfincompatibility in the tea plant (Camellia sinensis) might be under gametophytic control. BMC Genomics 17: 359. https://doi.org/10.1186/s12864-0162703-5. 